\section{The Stem Age Required for Floral Induction of Synchronized Mango Trees in the Tropics}

\author{
Fernando Ramírez ${ }^{4}$ \\ Facultad de Ciencias Biológicas, Pontificia Universidad Javeriana, Carrera \\ 7 No. 40-62, Bogotá, Colombia
}

Thomas L. Davenport ${ }^{1}$

Tropical Research and Education Center, IFAS, University of Florida, 18905 SW 280 Street, Homestead, FL 33031

\section{Gerhard Fischer ${ }^{2}$}

Facultad de Agronomía, Universidad Nacional de Colombia, Avenida Carrera 30 No 45-03, Bogotá, Colombia

\section{Julio Cesar Augusto Pinzón ${ }^{3}$ \\ Departamento de Filosofía, Facultad de Humanidades, Universidad Pedagógica Nacional, Calle 72 No. 11-86, Bogotá, Colombia}

Additional index words. Colombia, off season flowering, Mangifera indica, tip-pruning

Abstract. The quantitative floral inductive role of the age of the last vegetative flush was investigated in replicated trials of two cultivars of mango (Mangifera indica L.), Keitt and Tommy Atkins, growing in tropical conditions of Cundinamarca State in Colombia. Empirical observations have indicated that stems must be in rest for sufficient time, generally 4 to 5 months, to be induced to flower in the absence of cool temperatures. Twelve trees per cultivar were tip-pruned to stimulate a synchronous flush of vegetative growth at the beginning of the experiments. The first of four sets, each consisting of three replicate trees among the 12 , were sprayed with $4 \%$ potassium nitrate on a 2 -week schedule beginning 2 months after the pruning date. Biweekly sprays continued in this first set until a growth response was observed, whereupon the set was retired from further observations, and the second set of three synchronized trees began receiving biweekly spray treatments until they initiated a growth flush. The schedule continued through the four successive sets of trees until the age of stems necessary to induce a flowering response was determined. Treatment applications were quantified using a one-m-square quadrate to determine the numbers of resting stems and vegetative and /or reproductive shoots contained within. $\mathrm{KNO}_{3}$ sprays applied 3 months after the pruning date stimulated initiation of vegetatively induced shoots in both 'Keitt' and 'Tommy Atkins' trees. Synchronous generative shoot initiation in 'Keitt' trees occurred in $\approx 75 \%$ and $100 \%$ of the stems after $\mathrm{KNO}_{3}$ sprays applied 5 and 6 months after the pruning date, respectively. Tommy Atkins, a cultivar that is more difficult to induce to flower than 'Keitt', had $18 \%$ of shoots flowering after the 5 -month application and $100 \%$ flowering after the $\mathrm{KNO}_{3}$ application 6 months after the pruning date. None of the nontreated orchard trees flowered during this time. Stem age was the key factor correlated with flowering. The experimental trees, which were naturally habituated to experience two flowering periods per year, each within separate sections of tree canopy, were stimulated to produce one annual synchronized flowering event throughout the tree canopy as a result of the treatments.

Production of reproductive mango shoots occurs when they are initiated to grow from quiescent buds on resting stems exposed to cool, floral-inductive temperatures in sub-

\footnotetext{
Received for publication 19 Apr. 2010. Accepted for publication 28 July 2010.

We thank Marien for her valuable support.

${ }^{1}$ Senior Biologist.

${ }^{2}$ Associate Professor.

${ }^{3}$ Researcher.

${ }^{4}$ To whom reprint requests should be addressed; e-mail fernando.ramirez@javeriana.edu.co; fermp44@ yahoo.com.
}

tropical and high-latitude tropical climates (Davenport and Núñez-Elisea, 1997; NúñezElisea et al., 1996). In contrast, reproductive flushes generally occur after extended periods of stem rest in constantly warm temperatures of the low-latitude tropics (Bueno and Valmayor, 1974; Davenport, 2009; Davenport and Núñez-Elisea, 1997; NúñezElisea and Davenport, 1995). The age of the last flush of vegetative stems, thus, appears to be the primary factor regulating floral induction in warm climates. Bueno and Valmayor (1974) indicated that leaves must become brittle as evidenced by an audible crackling sound when hand-crushed to in- dicate leaf age. Núñez-Elisea (1986, 1988) reported that stems must be at least 6 months of age. Empirical observations (Davenport, 2006, 2009) have indicated that terminal stems (terminal intercalary units) must have attained a dark green color and achieved a minimum age of 4 months since the previous limp, red-leaf stage in easily induced cultivars and 5 months for the more recalcitrant cultivars to obtain a reproductive shoot response in the low-latitude tropics.

Frequent vegetative flush events occur in young trees and in mature trees in high fertility conditions with an abundance of water Such trees continually produce shoots that are induced to be vegetative as a result of short periods of stem rest between flushes (Davenport, 2003). Foliar-applied potassium, ammonium, or calcium nitrate stimulates shoot initiation of mango and is widely used in the low-latitude tropics to stimulate flowering (Núñez-Elisea and Caldeira, 1988). Potassium nitrate $\left(\mathrm{KNO}_{3}\right)$ is a water-soluble nitrate salt that is commonly used to stimulate flowering in numerous mango cultivars (Barba, 1974). It stimulates more vigorous flowering in mature stems than in younger ones (Bondad and Linsangan, 1979).

Previous anecdotal observations indicated that 'Haden' and 'Tommy Atkins' mango stems need to be at least 4 to 5 months old to reproductively respond to nitrate compounds. Insufficient stem maturity may, thus, explain the meager flowering response often observed in mango trees after spraying nitrates (Medina-Urrutia and Núñez-Elisea, 1997). To be successful in stimulating flowering, the nitrate salt must be applied after the resting stems of mango have reached sufficient age to overcome any inhibitory influence they may have on the flowering response (Davenport, 2000).

Davenport (2009) provided several lines of evidence to indicate that $\mathrm{KNO}_{3}$ as well as ammonium and calcium nitrate $\left[\mathrm{NH}_{4} \mathrm{NO}_{3}\right.$, $\mathrm{Ca}\left(\mathrm{NO}_{3}\right)_{2}$ ] initiate shoot growth but do not determine the inductive fate of bud morphogenesis. The ratio of the leaf-generated florigenic and vegetative promoters at the time of shoot initiation, not nitrate, is thought to be responsible for receptive buds to induce reproductive shoots. Kulkarni (2004) shared the view that the floral stimulus is already present in stems at the time that buds are forced in response to $\mathrm{KNO}_{3}$ and suggested that nitrates may also sensitize buds to the floral stimulus. Others have proposed that $\mathrm{KNO}_{3}$ is floralinductive in mango (Yeshitela et al., 2005). Alternately, nitrogen sufficiency achieved by potassium nitrate is considered a possible explanation (Kulkarni, 2004).

Another key factor when managing mango flowering is synchronization of vegetative growth in tree canopies, which allows all the stems in a canopy to be in the same physiological stage of maturity when $\mathrm{KNO}_{3}$ applications are made (Davenport, 2000). Synchronized growth is best accomplished by tippruning all terminal stems on trees (Davenport, 2003, 2006). Tip-pruning not only produces a specifically timed uniform flush of vegetative 
growth throughout the canopy, but it removes growth- and flower-inhibiting factors in stems derived from the previous season's flowering and fruiting panicles (Davenport, 2000, 2009). Tip-pruning mature trees quickly results in a synchronous flush of lateral vegetative shoots if water is adequate and leaf nitrogen levels are in a range of $1.1 \%$ to $1.4 \%$ (Davenport, 2003). If the lateral stems produced by this pruning event subsequently remain in rest for 4 or 5 months (depending on cultivar) in warm temperatures, then flowering will usually occur when shoots are initiated to grow by foliar application of potassium, calcium, or ammonium nitrate (Davenport, 2006).

The application of $\mathrm{KNO}_{3}$ to synchronized mature canopies has been empirically determined to be effective under tropical conditions as a mechanism to induce flowering. Programs have been adopted for the management of flowering in such orchards growing in warm tropical conditions (Davenport, 2003); however, the application of $\mathrm{KNO}_{3}$ and tip-pruning in flowering management strategies have not been thoroughly documented in replicated trials. A better understanding of the role that stem age plays in mango flowering is, therefore, needed. The aim of the current study was to establish the age of the previous vegetative flush necessary to induce flowering in synchronized 'Keitt' and 'Tommy Atkins' trees under warm, tropical conditions in Colombia.

\section{Materials and Methods}

The experiments were conducted on orchard trees at two farms, Finca Monterrey, and Finca Santa Rosa, located at Vereda Alto de las Flores, near the village of La Mesa

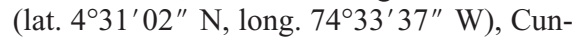
dinamarca State, Colombia. Finca Monterrey had nearly 300 15-year-old 'Keitt' mango trees that were 3 to $4 \mathrm{~m}$ in height. Finca Santa Rosa had $\approx 50$ 15-year-old 'Tommy Atkins' mango trees that were also 3 to $4 \mathrm{~m}$ in height. Tree spacing in both farms was $4 \mathrm{~m} \times 8 \mathrm{~m}$.

La Mesa is located on the eastern cordillera, $65 \mathrm{~km}$ northeast of Bogotá, at an elevation of $1300 \mathrm{~m}$ above sea level (Ramírez et al., 2010). The mean air temperature was a nearly constant $22{ }^{\circ} \mathrm{C}$ with a yearly precipitation of $\approx 1300 \mathrm{~mm}$ and average relative humidity of $\approx 70 \%$ (Ramírez et al., 2010). The region is mountainous with basically two climates, warm (maximum $36{ }^{\circ} \mathrm{C}$, minimum $24{ }^{\circ} \mathrm{C}$, and mean $28{ }^{\circ} \mathrm{C}$ ) in the lower valleys and moderately warm (maximum $27{ }^{\circ} \mathrm{C}$, minimum $18{ }^{\circ} \mathrm{C}$, and mean $22{ }^{\circ} \mathrm{C}$ ) on the upper hillsides (Ortiz, 1996). There are two annual rainy seasons extending from February to May and September to December that result in two annual flowering seasons that occur after the onset of each rainy season. These events result in two harvest seasons per year occurring 4 ('Tommy Atkins') and 6 ('Keitt') months after each flowering period (Ramírez et al., 2010).

The most important environmental factor governing the time to initiate the experiment was the onset of the rainy season because this is the time of the year when trees have plenty of water to promote growth. Trees were pruned at the start of the rainy season because they were likely to receive sufficient water for shoot initiation (Ramírez et al., 2010). Leaf nitrogen concentration in representative randomly selected leaves from the terminal intercalary unit of each cultivar was $1.4 \%$.

Microelements were applied uniformly to the soil around all treatment trees before the start date to correct deficiencies that were noted in the pre-treatment leaf analyses. A total of $68 \mathrm{~g}$ per tree of a balanced mixture of microelements containing manganese sulfate $(22.5 \%)$, copper sulfate $(4.8 \%)$, zinc sulfate $(35.7 \%)$, boric acid $(12.2 \%)$, calcium sulfate $(5.3 \%)$, and sulfur $(19.1 \%)$ was uniformly applied to all experimental trees.

Twelve trees per cultivar were tip-pruned at the start date to stimulate a uniform flush of lateral vegetative shoots throughout the canopies of all trees. These shoots were allowed to develop into numerous synchronized lateral stems to evaluate the effect of stem age on floral initiation after $\mathrm{KNO}_{3}$ application. The start dates for 'Tommy Atkins' at Finca Santa Rosa was 20 Jan. 2007 and 3 Feb. 2007 for 'Keitt' trees at Finca Monterrey. Stems were pruned with shears $\approx 0.3 \mathrm{~m}$ back from the tips, thus removing most of the leaves in the canopy to ensure a vegetative response (Ramírez et al., 2010). Deeper cuts were avoided to prevent a possible early second flush of vegetative growth during the course of the experiment (Davenport, 2006). The cuts were performed on greater than $95 \%$ of the stems on each tree to ensure synchronous vegetative shoot initiation throughout the canopies.

The 12 tip-pruned trees of each cultivar were randomly divided into four sets of three replicate trees designated $\mathrm{S} 1, \mathrm{~S} 2, \mathrm{~S} 3$, and $\mathrm{S} 4$. Subsequent appropriately timed $\mathrm{KNO}_{3}$ spray treatments to the four different sets of trees targeted the now dormant lateral stems. The experimental design was a split-plot arrangement with cultivars as main plots and tree sets as subplots. A control (no spraying) was not included because non-sprayed trees from $\mathrm{S} 2$, $\mathrm{S} 3$, and S4 served as controls for S1, S2, and $\mathrm{S} 3$ trees, respectively. Beginning 2 months after the pruning dates, biweekly spray applications of $\mathrm{KNO}_{3}$ started in the three $\mathrm{S} 1$ trees of each cultivar. The purpose of the different sets was to provide similarly synchronized trees such that when one set responded to a $\mathrm{KNO}_{3}$ spray treatment, that set could be retired from further treatments and subsequent treatments could be applied to the next, resting set of trees to maintain a schedule of accumulating age in the synchronized stems as they matured over time. The S1 trees of 'Tommy Atkins' were first sprayed at Finca Santa Rosa on 17 Mar. 2007 and the S1 set of 'Keitt' trees was first sprayed at Finca Monterrey on 31 Mar. 2007. Apical buds of the lateral stems of sprayed trees were observed 2 weeks after each application to note any growth response to that spray. The planned protocol was that if apical shoot initiation occurred in a set of trees after a particular spray application or if a maximum of four non-responsive sprays was recorded, the set was to be retired from further treatment and observation and the next numbered set was to be sprayed for the first time on the next scheduled spray date. Set 1 trees were, thus, sprayed with $\mathrm{KNO}_{3}$ every 2 weeks after the first application at 2 months after the pruning date, and biweekly sprays continued until an apical bud growth response was observed at which time the S1 trees were retired, and data (number of non-responsive resting stems and the type, i.e., vegetative or reproductive, of initiating shoots on responsive stems) were recorded. The biweekly spray schedule continued in the S2 trees starting 2 weeks after the last spray to the $\mathrm{S} 1$ trees (same day as the S1 shoot growth response was observed). Set 2 trees were then sprayed biweekly until a growth response was observed 2 weeks after the last application, at which time the S2 trees were retired and data similarly recorded. Spray applications similarly continued on the biweekly schedule in S3 and ultimately S4 trees.

On each designated treatment day, the undersides of all leaves of the three trees in the scheduled set were thoroughly sprayed to the point of dripping with $4 \%$ water-soluble $\mathrm{KNO}_{3}$. Adjusting the sprayer nozzle to a coarse setting prevented drift to other trees. Spray treatments were applied using an enginedriven mechanical backpack sprayer equipped with a wand to ensure complete coverage.

Tree responses were quantified within a 1-m-square quadrate made with polyvinyl chloride pipe placed on the four cardinal sides of each tree according to a compass in each set of three replicate trees (Fig. 1). Placement of the quadrate on trees was random using closed eyes when approaching tree canopies from each direction. The number of stems captured within the quadrate and the number and type of new apical shoots emerging from those stems were recorded once all of the emerging shoots could be clearly identified as vegetative or reproductive. When no new shoots emerged, i.e., stems remained in rest by 2 weeks after a spray treatment, data were recorded as zero shoot initiation. The proportions of reproductive, vegetative, and resting shoots as a function of the number of shoots per quadrate per cardinal point in each cultivar were analyzed by analysis of variance (Statgraphics, 5.0, 2005; Statpoint Inc., Herndon, VA).

\section{Results}

'Keitt' trees. Synchronous vegetative shoot initiation from lateral buds began $\approx 2$ weeks after pruning all sets (S1 to S4) of the 12 'Keitt' trees at Finca Monterrey. The leaves of these trees developed to the limpred-leaf stage with dormant apical buds throughout the canopy by 1 month after tippruning and then became light green within 2 weeks after that. The stems in each of the four sets of 'Keitt' trees remained in rest throughout the 6-month course of the experiment unless stimulated to initiate shoots in response to $\mathrm{KNO}_{3}$ spray at the designated time. The resting stems in the $\mathrm{S} 1$ trees did not respond to the 2.0- or 2.5-month $\mathrm{KNO}_{3}$ spray applications and remained in rest until 
responding to the 3.0-month application when vegetative shoots initiated in an average $5 \%$ of stems per quadrate (Fig. 2). The remaining $95 \%$ of stems stayed in rest in this set. No shoot initiation from resting stems occurred in the three replicate $\mathrm{S} 2$ trees after $\mathrm{KNO}_{3}$ spray applications at 3.5, 4.0, or 4.5 months after the pruning event. The first shoot initiation responses occurred after the 5.0-month treatment of S2 trees wherein an average of $76 \%$ of stems produced reproductive shoots. The balance $(24 \%)$ of the stems in the three trees remained in rest by 2 weeks after treatment (Fig. 2; Table 1). The S3 set of trees was sprayed with $\mathrm{KNO}_{3} 5.5$ months after the pruning event. An average of $90 \%$ of stems within the four quadrates among the three replicate trees initiated reproductively induced shoots in response to the spray treatment. The remaining $10 \%$ of stems stayed in rest by 2 weeks after treatment (Fig. 2; Table $1)$. One hundred percent of the stems on resting S4 trees that were treated on Month 6.0 after the pruning event responded with only reproductive shoots in each of the three replicate trees (Fig. 2; Table 1). The average proportions of stems initiating reproductive shoots were similar among the cardinal sides of the trees according to analysis of variance $(P>0.05)$ (Tables 1 and 2). Orchard 'Keitt' trees surrounding the experimental plot did not flower at any time during the course of the

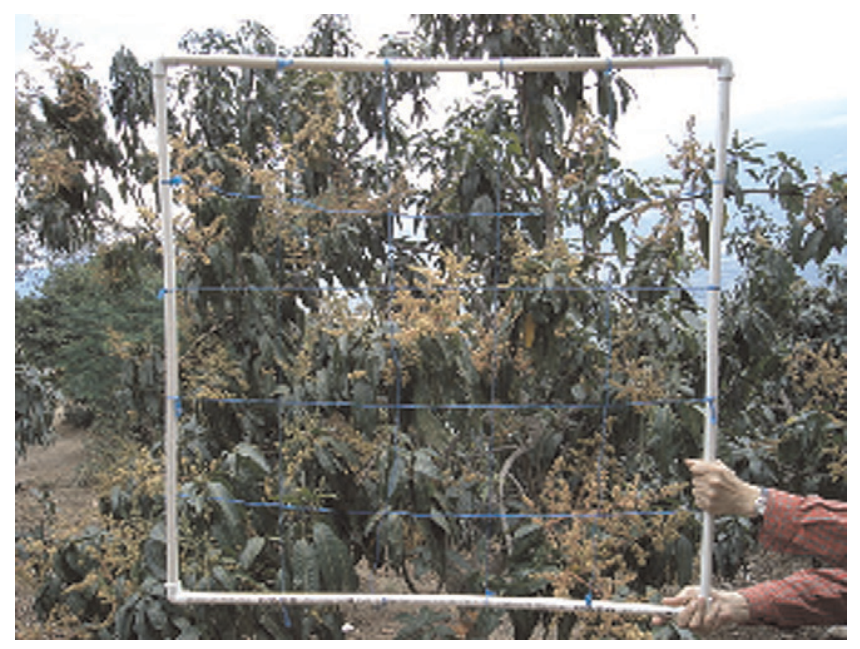

Fig. 1. The proportions of resting stems and reproductive and vegetative shoot types in 'Tommy Atkins' and 'Keitt' trees were recorded using a $1 \times 1-\mathrm{m}$-square quadrate placed against the four cardinal sides of each experimental tree.

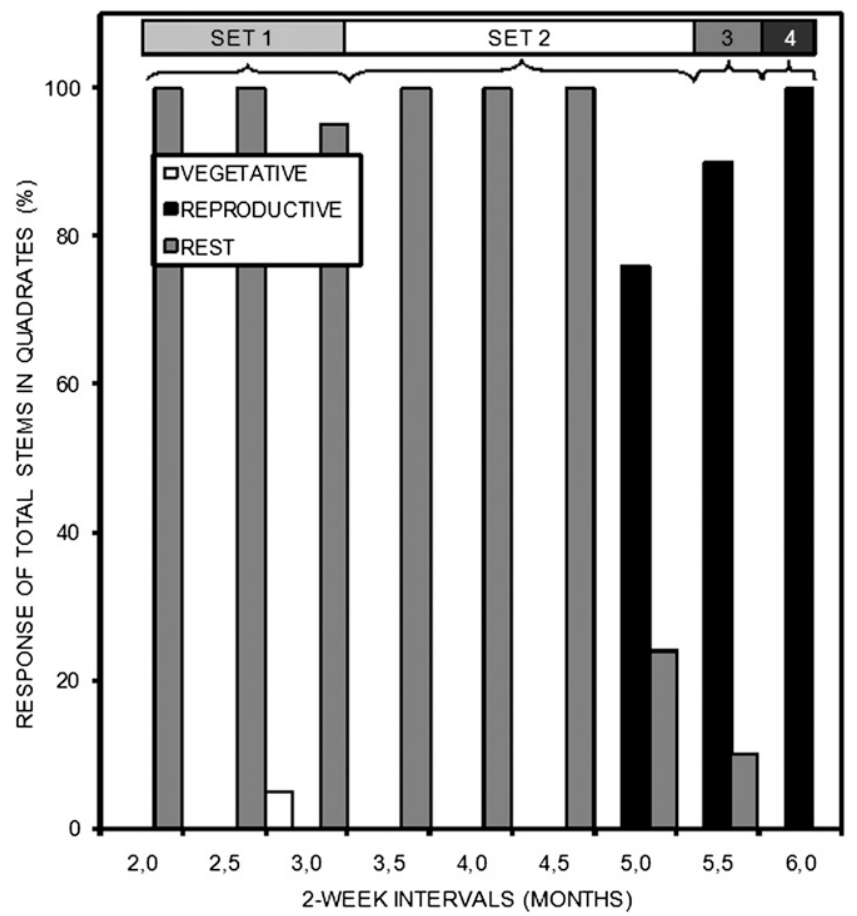

Fig. 2. Percent of reproductive and vegetative shoots and resting stems observed in four 'Keitt' sets sprayed with potassium nitrate at the indicated time after tip-pruning trees at Finca Monterrey.

experiment indicating that outside influences did not cause the observed flowering responses in the test trees.

'Tommy Atkins' trees. Synchronous initiation of lateral vegetative shoots occurred throughout the canopy of all 12 'Tommy Atkins' trees $\approx 2$ weeks after pruning at Finca Santa Rosa. Shoots were fully elongated in the limp-red-leaf stage of development with a dormant apical bud by 1 month after pruning. They then became light green in color within 2 weeks. These new stems in the S1 trees did not respond to the 2.0- or 2.5-month post-prune $\mathrm{KNO}_{3}$ sprays. The 3.0-month spray treatment, however, resulted in vegetative shoot initiation in $5 \%$ of the stems 2 weeks after application. The balance of stems in this set remained in rest (Fig. 3).

No shoot initiation (vegetative or reproductive) occurred in response to the next three biweekly sprays applied to the S2 'Tommy Atkins' trees at 3.5, 4.0, and 4.5 months after tip-pruning. The $\mathrm{S} 2$ trees remained in rest during this period despite the $\mathrm{KNO}_{3}$ sprayings. The fourth spray, however, applied at 5.0 months after tip-pruning of the 'Tommy Atkins' trees stimulated initiation of floral-induced shoots in an average of $17 \%$ of the stems captured in each quadrate in S2 trees at 5.5 months after pruning. Eighty-three percent of the S2 stems remained in rest (Fig. 3; Table 2).

More reproductive shoots were observed in response to $\mathrm{KNO}_{3}$ sprays as stems became older. For example, the next biweekly $\mathrm{KNO}_{3}$ spray was applied to S3 'Tommy Atkins' trees at 5.5 months after the tip-pruning date. It stimulated initiation of floral-induced shoots in an average of $55 \%$ of stems, as observed 2 weeks later at 6 months after the tip-pruning date (Fig. 3; Table 2). Forty-five percent of these stems remained in rest. The $\mathrm{KNO}_{3}$ spray applied to the S4 'Tommy Atkins' trees at 6.0 months stimulated the greatest reproductive response with an average $100 \%$ of the stems producing reproductive shoots 2 weeks later at 6.5 months after tip-pruning (Fig. 3; Table 2). The average proportion of reproductive shoots captured in the quadrate was the same among all cardinal points according to analysis of variance $(P>0.05)$. Like in the 'Keitt' orchard, none of the 'Tommy Atkins' trees surrounding the test plot flowered during the course of the experiment.

\section{Discussion}

The present study provides the first replicated experiments in the tropics investigating the impact of stem age on flowering. Synchronized floral induction was achieved in two cultivars in Cundinamarca State, Colombia. All results were consistent with previously described empirical observations.

Synchronous vegetative shoot formation in both the 'Keitt' and 'Tommy Atkins' trees was a typical response to tip-pruning. Vegetatively induced initiation again occurred in response to the 3-month sprays with an average of $5 \%$ of stems initiating vegetative shoots in both cultivars. This vegetative response at 3 months after the pruning event 
Table 1. Total average number ( $\pm \mathrm{SE})$ of stems, number of shoots, and shoots per stem on randomly selected quadrates in 'Keitt' mango in Finca Monterrey since experiment start date on 3 Feb. 2007.

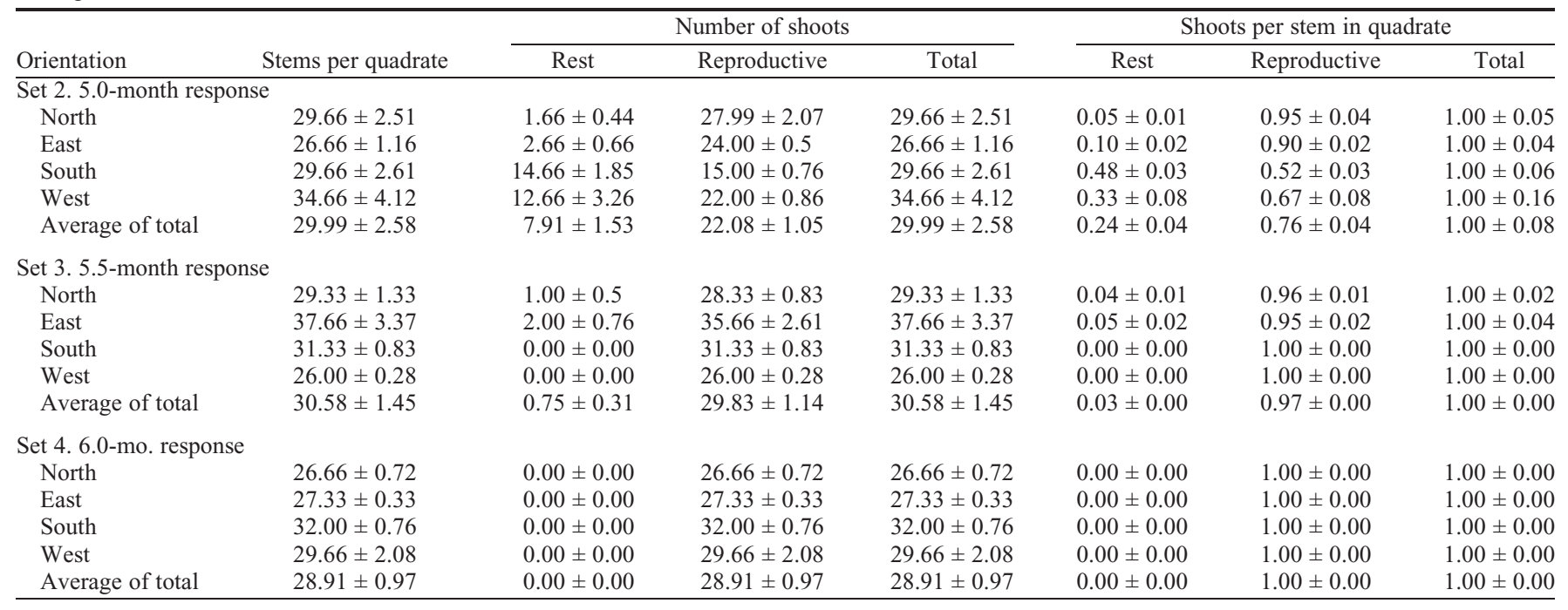

Table 2. Total average number ( $\pm \mathrm{SE}$ ) of stems, number of shoots, and shoots per stem on randomly selected quadrates in 'Tommy Atkins' mango in Finca Santa Rosa since experimental starting date on 20 Jan. 2007.

\begin{tabular}{|c|c|c|c|c|c|c|c|}
\hline \multirow[b]{2}{*}{ Orientation } & \multirow[b]{2}{*}{ Stems per quadrate } & \multicolumn{3}{|c|}{ Number of shoots } & \multicolumn{3}{|c|}{ Shoots per stem in quadrate } \\
\hline & & Rest & Reproductive & Total & Rest & Reproductive & Total \\
\hline North & $26.00 \pm 7.28$ & $18.33 \pm 4.60$ & $7.66 \pm 2.68$ & $26.00 \pm 7.28$ & $0.82 \pm 0.05$ & $0.18 \pm 0.05$ & $1.00 \pm 0.10$ \\
\hline West & $18.66 \pm 7.99$ & $13.00 \pm 3.25$ & $5.66 \pm 4.74$ & $18.66 \pm 7.99$ & $0.80 \pm 0.05$ & $0.20 \pm 0.05$ & $1.00 \pm 0.10$ \\
\hline Average of total & $21.33 \pm 9.96$ & $15.58 \pm 4.34$ & $5.75 \pm 5.62$ & $21.33 \pm 9.96$ & $0.82 \pm 0.05$ & $0.18 \pm 0.05$ & $1.00 \pm 0.10$ \\
\hline \multicolumn{8}{|c|}{ Set 3. 5.5-month response } \\
\hline South & $26.66 \pm 7.65$ & $11.33 \pm 3.65$ & $15.33 \pm 4.00$ & $26.66 \pm 7.65$ & $0.44 \pm 0.14$ & $0.56 \pm 0.14$ & $1.00 \pm 0.28$ \\
\hline West & $29.00 \pm 7.85$ & $15.00 \pm 3.81$ & $14.00 \pm 4.04$ & $29.00 \pm 7.85$ & $0.53 \pm 0.14$ & $0.47 \pm 0.14$ & $1.00 \pm 0.28$ \\
\hline Average of total & $28.41 \pm 7.07$ & $12.75 \pm 3.62$ & $15.66 \pm 3.45$ & $28.41 \pm 7.07$ & $0.45 \pm 0.12$ & $0.55 \pm 0.12$ & $1.00 \pm 0.24$ \\
\hline \multicolumn{8}{|c|}{ Set 4. 6.0-month response } \\
\hline North & $26.33 \pm 1.20$ & $0.00 \pm 0.00$ & $26.33 \pm 1.20$ & $26.33 \pm 1.20$ & $0.00 \pm 0.00$ & $1.00 \pm 0.00$ & $1.00 \pm 0.00$ \\
\hline East & $18.66 \pm 0.88$ & $0.00 \pm 0.00$ & $18.66 \pm 0.88$ & $18.66 \pm 0.88$ & $0.00 \pm 0.00$ & $1.00 \pm 0.00$ & $1.00 \pm 0.00$ \\
\hline
\end{tabular}

has been observed several times in growerassisted trials with the exception that it usually occurs in more stems of the canopy. Recent results of experiments in which $4 \%$ $\mathrm{KNO}_{3}$ was foliar applied to 2-month-old stems of 'Keitt' and 'Tommy Atkins' trees (3 months after tip-pruning) growing in the Dominican Republic resulted in $100 \%$ vegetative shoots. In contrast, application of the same spray treatment in the same season to 4.5- and 5.5-month-old stems to the same cultivars ( $\approx 5$ and 6 months after tip-pruning), respectively, resulted in $100 \%$ reproductive shoots with a fourfold increase in mango yield over previous seasons as a result of the increased number of stems bearing inflorescences (Davenport and Oleo, unpublished data).

The lack of shoot initiation after $\mathrm{KNO}_{3}$ sprays to 'Keitt' or 'Tommy Atkins' trees 2.0 and 2.5 months after the pruning date may be linked to a low cytokinin to auxin ratio in young buds as part of the initiation cycle. Davenport (2009) and Davenport and NúñezElisea (1997) suggested that shoot initiation in resting stems of mango is governed by a rising cytokinin to auxin ratio acting to naturally stimulate bud break once a critical ratio is reached. This hypothesis is supported by high levels of auxin typically found in young mango shoots (Chen, 1987), a gradual reduction in auxin concentration (Jacobs, 1962), transport capacity with age (Davenport et al.,1980), and the inhibition of bud break as auxin concentration decreases (Davies, 1995). This decreasing impact of auxin in stems is coupled with the initially low level but gradual accumulation of cytokinins translocated from roots to stems as they age (Hendry et al., 1982a, 1982b) and consequent stimulation of bud break (Davenport, 1990; Davies, 1995). It is analogous to the cytokinin-auxin relationships described for correlative inhibition of lateral branching (apical dominance) in growing plants (Cline et al., 1997). Cytokinin to auxin ratios in the young stems may, therefore, not have been sufficiently high to stimulate shoot initiation despite applications of $\mathrm{KNO}_{3}$. Whereas accumulating evidence indicates that such hormonal interactions may explain the resistance of young stems to shoot initiation treatments, it does not explain why the stems were again resistant to shoot initiation as they matured from 3.5 to 4.5 months after tippruning. We currently have no explanation for this phenomenon unless $\mathrm{GA}_{3}$ may be interacting with auxin to preserve bud dormancy during this latter period as was suggested by Davenport et al. (2001).

A total of four $\mathrm{KNO}_{3}$ sprays were applied to the $\mathrm{S} 2$ trees of both cultivars before floral induction occurred in response to the 5-month spray treatment. Response at 5 months was correlated with the age of the stems. In contrast, the trees of Sets 3 and 4 flowered in response to only one $\mathrm{KNO}_{3}$ spray after stems had attained 5.5 and 6.0 months of age at the time of treatment. The $\mathrm{KNO}_{3}$ sprays, therefore, did not have a cumulative effect on floral induction. Nor did $\mathrm{KNO}_{3}$ itself induce flowering because it stimulated a vegetative response in younger stems. The reproductive response and the intensity of that response were governed 


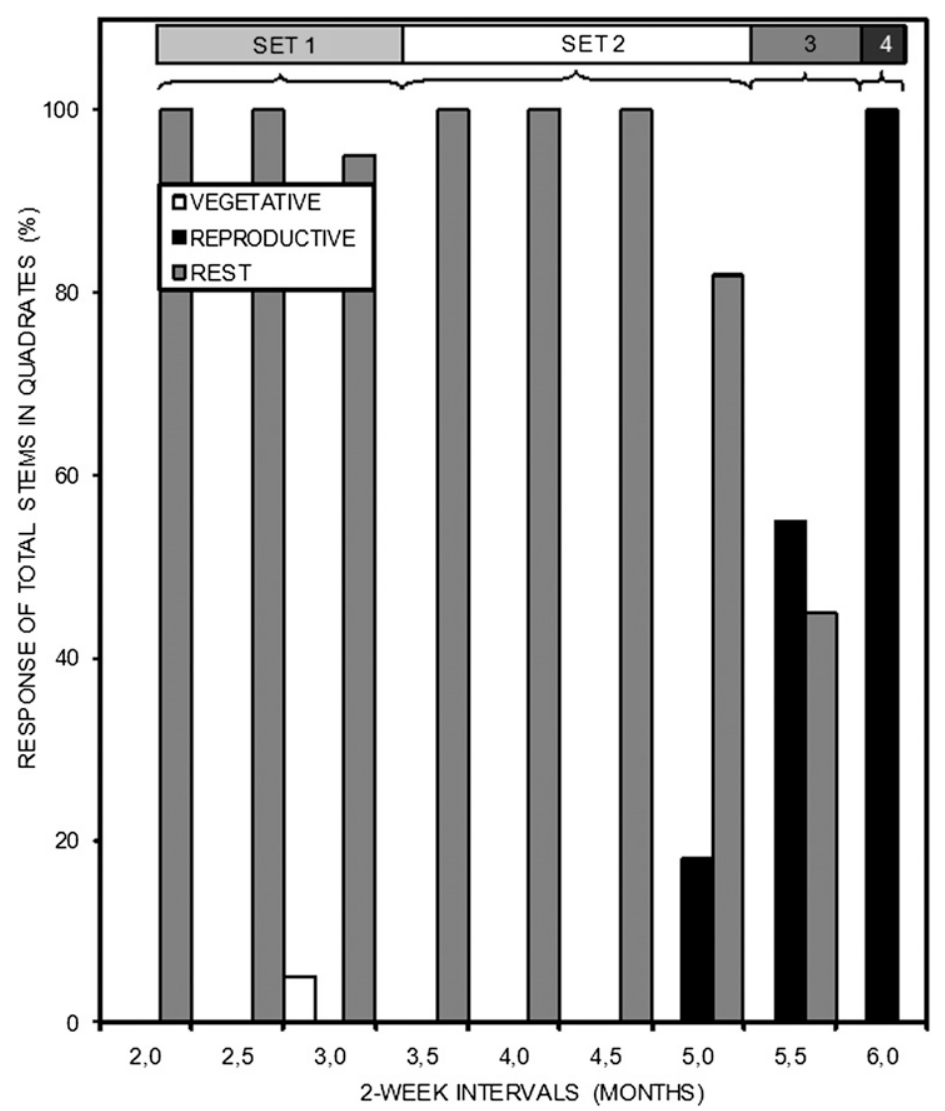

Fig. 3. Percent of reproductive and vegetative shoots and resting stems observed in the four 'Tommy Atkins' sets sprayed with potassium nitrate at the indicated time after tip-pruning trees at Finca Santa Rosa.

by changing endogenous conditions as the stems aged. 'Tommy Atkins' is known to require more time to induce flowering after synchronized pruning than does 'Keitt' (Davenport, 2003), and the quantitative results obtained in our experiments bore this out.

To explain a consistent mechanism of mango flowering in both the tropics and subtropics, floral induction when shoot initiation occurs has been suggested to be determined by the interaction of a florigenic promoter (FP), which is produced at a low basal level in warm temperatures and upregulated in cool temperatures (Davenport et al., 2006; Ramírez et al., 2010), with a vegetative promoter (VP). The VP appears to be initially produced in high quantities in young shoots to stimulate vegetatively induced responses even in floralinductive, cool temperatures but decreases with stem age (Núñez-Elisea and Davenport, 1995). The short-lived, temperature-regulated FP is the protein product of one or more of three orthologs of the FT gene described in Arabidopsis and recently discovered in mango, and it has been demonstrated by many to translocate to buds to induce flowering (Davenport, 2009). The putative age-dependent VP may be a gibberellin or closely associated with the gibberellin synthesis pathway as evidenced by the promotive impact of the triazole class of gibberellin synthesis inhibitors on mango flowering (Davenport, 2009). Our results from the current study support the hypothesis that the increasing ratio of the FP/ VP through the gradual decrease in VP with stem age is conducive to flowering. Floral induction in response to stem age proved to be cultivar-specific for 'Keitt' and 'Tommy Atkins' trees, because more time since pruning of the original stems ( 2 weeks) was required by 'Tommy Atkins' to induce full flowering.

Asynchronous flowering and vegetative flushes naturally occur two times per year throughout the canopy in the orchards at $\mathrm{La}$ Mesa. Approximately half of the stems on each tree initiate reproductive shoots, and the other portion of stems initiates vegetative shoots in the first flowering season each year. During the second flowering season, the stems originating as vegetative shoots in the previous season become mature enough for floral induction to occur in newly emerging apical shoots. The stems that bore terminal inflorescences in the previous season initiate vegetatively induced lateral shoots from stems bearing either the terminal scar of abscised floral rachises or retained dried rachises from the previous flowering season (Ramírez et al., 2010). Tip-pruning proved effective as a means to synchronize a vegetative flush of growth throughout the canopies in the initial part of the treatment schedule. By pruning, synchronized trees switched from biannual (half of the stems flowered during each of two seasons) to annual (all of the stems flowered in synchrony).

Foliar sprays of $\mathrm{KNO}_{3}, \mathrm{Ca}\left(\mathrm{NO}_{3}\right)_{2}, \mathrm{NH}_{4} \mathrm{NO}_{3}$, or ethephon have been used to stimulate offseason flowering of mango, especially in tropical regions, for many years (Bondad and Linsangan, 1979). Chemical bud forcing is most effective in tropical regions where distinct wet and dry seasons prevail. Previous research in non-synchronized orchards showed that stimulation of flowering with nitrates was often inconsistent (Núñez-Elisea, 1986). The problem with such treatments is that multiple biweekly applications are needed to achieve a flowering response in all sections of tree canopies as a result of the varying ages of the stems in them. Trees must then be harvested several times to obtain fruit at the desired stage of horticultural maturity. Synchronizing the age of the last flush in the 'Keitt' and 'Tommy Atkins' trees in the current experiments in Colombia confirmed our ability to induce offseason flowering using one properly timed $\mathrm{KNO}_{3}$ spray application to obtain a full canopy bloom provided the right water and nutrient demands are met.

Growers can achieve off-season mango flowering by using a flowering management program. They are advised to spray two or three representative test trees in their orchards that have been in rest for 5 or 6 months after tip-pruning in easy- and hard-to-flower cultivars, respectively. When no response to the spray occurs after 2 weeks, trees should be resprayed. Flowering usually occurs after the second spray application, but if it is not observed, spray applications should continue on a biweekly basis until a flowering response is obtained. Once growers observe a full response from these test trees, they should then immediately apply the treatment to sections or the entire orchard as desired, depending on the tip-pruning schedule. Large orchards can be split into sections and be induced to flower according to a flowering management program. A predictable synchronous flowering flush can be dependably achieved with one spray application without the need for additional horticultural tools such as plant growth retardants. Moreover, the tip-pruning event removes floral-inhibiting rachises and increases the number of bearing stems on each tree resulting in elimination of alternate bearing and a substantial increase in annual yields.

\section{Literature Cited}

Barba, R.C. 1974. Induction of flowering of the mango by chemical spray. Proc. Crop Sci. Soc. Phil. 5:154-160.

Bondad, N.D. and E. Linsangan. 1979. Flowering in mango induced with potassium nitrate. HortScience 14:527-528.

Bueno, P.B. and R.V. Valmayor. 1974. Potassium nitrate: Key to mango flowering. Agriculture Los Baños 13:4-16.

Chen, W.S. 1987. Endogenous growth substances in relation to shoot growth and flower bud development of mango. J. Amer. Soc. Hort. Sci. 112:360 363.

Cline, M., T. Wessel, and H. Iwamura. 1997. Cytokinin/auxin control of apical dominance in Ipomoea nil. Plant Cell Physiol. 38:659667.

Davenport, T.L. 1990. Citrus flowering. Hort. Rev. (Amer. Soc. Hort. Sci.) 12:349-408.

Davenport, T.L. 2000. Processes influencing floral initiation and bloom: The role of phytohormones in a conceptual flowering model. HortTechnology 10:733-739. 
Davenport, T.L. 2003. Management of flowering in three tropical and subtropical fruit tree species. HortScience 38:1331-1335.

Davenport, T.L. 2006. Pruning strategies to maximize tropical mango production from the time of planting to restoration of old orchards. HortScience 41:544-548.

Davenport, T.L. 2009. Reproductive physiology, p. 97-169. In: Litz, R.E. (ed.). The mango: Botany, production and uses. CAB International, Wallington Oxon, UK.

Davenport, T.L., P.W. Morgan, and W.R. Jordan. 1980. Reduction of auxin transport capacity with age and internal water deficits in cotton petioles. Plant Physiol. 65:1023-1025.

Davenport, T.L. and R. Núñez-Elisea. 1997. Reproductive physiology, p. 69-146. In: Litz, R.E. (ed.). The mango: Botany, production and uses. CAB International, Wallington Oxon, UK.

Davenport, T.L., D.W. Pearce, and S.B. Rood. 2001. Correlation of endogenous gibberellic acid with initiation of mango shoot growth. J. Plant Growth Regul. 20:308-315.

Davenport, T.L., Z. Ying, V. Kulkarni, and T.L. White. 2006. Evidence for a translocatable florigenic promoter in mango. Sci. Hort. 110: $150-159$.
Davies, P.J. 1995. Plant hormones: Physiology, biochemistry and molecular biology. Kluwer Academic Publishers, Boston, MA.

Hendry, N.S., J. Van Staden, and P. Allan. 1982a. Cytokinins in citrus. I. Fluctuations in the leaves during seasonal and developmental changes. Sci. Hort. 16:9-16.

Hendry, N.S., J. Van Staden, and P. Allan. 1982b. Cytokinins in citrus. II. Fluctuations during growth in juvenile and adult plants. Sci. Hort. 17:247-256

Jacobs, W.P. 1962. Longevity of plant organs: Internal factors controlling abscission. Annu. Rev. Plant Physiol. 13:403-436.

Kulkarni, V.J. 2004. The tri-factor hypothesis of flowering in mango. Acta Hort. 645:61-70.

Medina-Urrutia, V. and R. Núñez-Elisea. 1997. Summer promotion of vegetative shoots to increase early flowering response of mango trees to ammonium nitrate sprays. Acta Hort. 455:188-201.

Núñez-Elisea, R. 1986. Producción temprana de mango 'Haden' y 'Manila' con aspersiones de nitrato de potasio. SARH-INIFAP-CIAPAC, Campo Agrícola Experimental Tecoman. Folleto para productores No. 8 .

Núñez-Elisea, R. 1988. Nitrato de amonio: Nueva alternativa para adelantar la floración y cosecha del mango. SARH-INIFAP-CIFAP COLIMA,
Campo Experimental Tecoman. Desplegable para productores No. 4

Núñez-Elisea, R. and M.L. Caldeira. 1988. Induction of flowering in mango (Mangifera indica L.) within ammonium nitrate sprays. HortScience 23:883.

Núñez-Elisea, R. and T.L. Davenport. 1995. Effect of leaf age, duration of cool temperature treatment, and photoperiod on bud dormancy release and floral initiation in mango. Sci. Hort. 62:63-73.

Núñez-Elisea, R., T.L. Davenport, and L.M. Caldeira. 1996. Control of bud morphogenesis in mango (Mangifera indica L.) by girdling, defoliation and temperature modification. J. Hort. Sci. 71:25-39.

Ortiz, A.P. 1996. Diccionario geográfico de Colombia: Corcovada-Lynval and Cove. Tomo 2. Tercera edición. IGAC, Bogotá, Colombia.

Ramírez, F., T.L. Davenport, and G. Fischer. 2010. The number of leaves required for floral induction and translocation of the florigenic promoter in mango (Mangifera indica L.) in a tropical climate. Sci. Hort. 123:443-453.

Yeshitela, T., P.J. Robbertse, and P.J.C. Stassen. 2005. Potassium nitrate and urea sprays affect flowering and yields of 'Tommy Atkins' (Mangifera indica L.) mango in Ethiopia. South Afr. J. Plant Soil 22:28-32. 